\title{
Publisher's Note: Depolarizing field in ultrathin electrocalorics [Phys. Rev. B 92, 064101 (2015)]
}

\section{E. Glazkova, C.-M. Chang, S. Lisenkov, B. K. Mani, and I. Ponomareva}

(Received 9 December 2015; published 22 December 2015)

DOI: 10.1103/PhysRevB.92.219905

PACS number(s): 77.55.fg, 77.22.Ej, 77.70.+a, 99.10.Fg

This paper was published online on 5 August 2015 with an error in the author affiliation list. The author affiliation list should read as

E. Glazkova, ${ }^{1}$ C.-M. Chang, ${ }^{1,2}$ S. Lisenkov, ${ }^{1}$ B. K. Mani, ${ }^{1}$ and I. Ponomareva ${ }^{1}$

${ }^{1}$ Department of Physics, University of South Florida, Tampa, Florida 33620, USA

${ }^{2}$ Institute for Cyber-Enabled Research, Michigan State University, Biomedical \& Physical Sciences Building, 567 Wilson Road, Room 1440, East Lansing, Michigan 48824-1226, USA

The paper has been corrected as of 9 December 2015. The author affiliation list is incorrect in the printed version of the journal. 